Check for updates

Cite this: RSC Adv., 2018, 8, 36360

\title{
Adsorption of $\mathrm{ng} \mathrm{L}^{-1}$-level arsenic by ZIF-8 nanoparticles: application to the monitoring of environmental water $\dagger$
}

\author{
Durga Parajuli, (DD *a Kiwamu Sue, (iD ${ }^{\text {b }}$ Akira Takahashi, (iD ${ }^{a}$ Hisashi Tanaka (D) a \\ and Tohru Kawamoto (iD *a
}

\begin{abstract}
The provisional contamination level of arsenic in drinking water is $10 \mu \mathrm{g} \mathrm{L}^{-1}$. For decreasing this value to a safer level, a more precise method for analyzing dissolved arsenic is required. With this aim, we synthesized zeolitic imidazolate framework-8 (ZIF-8) in the aqueous phase and characterized its potential application for monitoring the trace arsenic in fresh water. In this regard, we report following three notable outcomes. First, we demonstrate the excellent performance of ZIF-8 nanoparticles (nZIF8) for the adsorption of $\mathrm{ng} \mathrm{L}^{-1}$ levels of $\mathrm{AsO}_{4}{ }^{3-}$. $\mathrm{nZIF-8}$ is able to adsorb over $99 \%$ of arsenic from as low

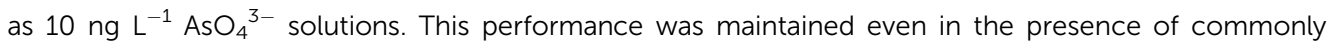
coexisting anions, for example, $>90 \%$ adsorption from a $0.1 \mu \mathrm{g} \mathrm{L}^{-1}$ arsenic solution was observed in the presence of $10 \mathrm{mg} \mathrm{L}^{-1}$ of $\mathrm{Cl}^{-}, \mathrm{NO}_{3}{ }^{-}, \mathrm{CO}_{3}{ }^{2-}$, or $\mathrm{SO}_{4}{ }^{2-}$, or $1 \mathrm{mg} \mathrm{L}^{-1}$ of $\mathrm{PO}_{4}{ }^{3-}$. Second, we clarified that the mechanism of arsenic adsorption by $\mathrm{ZIF}-8$ is simply a ligand exchange process, in which the $\mathrm{As}(\mathrm{V})$ oxide anion replaces the imidazolate unit in the framework. Third, we propose a handy scheme for the analysis of $\mathrm{ng} \mathrm{L}^{-1}$ levels of arsenic in drinking water, in which $\mathrm{nZIF-8}$ is used for the concentration of trace level $\mathrm{AsO}_{4}{ }^{3-}$. By doing this, as low as $100 \mathrm{ng} \mathrm{L}^{-1}$ arsenate in drinking water can be quantified by colorimetric analysis, the detection limit of which is $5 \mu \mathrm{g} \mathrm{L}^{-1}$ in pure water. The application of this scheme is expected to highly enhance $\mathrm{AsO}_{4}{ }^{3-}$ detection first by concentrating it to an easily detectable range, and second by excluding the majority of interfering ions present in the system. Therefore, a reduction in the minimum quantifying limit of arsenic in fresh water to as low as $1 \mathrm{ng} \mathrm{L}^{-1}$ can be expected if the method is coupled with ICP-MS.
\end{abstract}

Received 19th September 2018 Accepted 18th October 2018

DOI: $10.1039 / c 8 \mathrm{ra07776b}$

rsc.li/rsc-advances example, it is possible to detect $<1 \mu \mathrm{g} \mathrm{\textrm {L } ^ { - 1 }}$ as long as the concentration of other elements remains below interference levels. However, such equipment is not available to all drinking water reservoirs. Moreover, since the concentration of any element in natural water is seldom fixed, periodic analysis is necessary. Under such circumstances, practical analytical methods are required to monitor the arsenic concentration in a given system at any time.

A number of colorimetric methods are currently in use for the estimation of arsenic at the $\mu \mathrm{g} \mathrm{L}^{-1}$ level. ${ }^{6}$ These are usually good tools for semi-quantitative estimation as the concentration of other elements is within the interference level. For example, many colorimetric methods targeted for $\mu \mathrm{g} \mathrm{L}^{-1}$ levels cannot detect arsenic in seawater or sewage water. Under such conditions, ICP-MS or graphite-furnace AAS can be good options. However, the detection limit of these instruments is also in the sub-ppb range and difficult to replicate in solutions containing several other elements. The same issue is true for other high-precision methods such as anodic or cathodic stripping voltammetry. ${ }^{7-10}$

In particular, the evaluation of $\mathrm{As}(\mathrm{v})$ is crucial. In general, inorganic arsenic in natural water exists in protonated oxide 


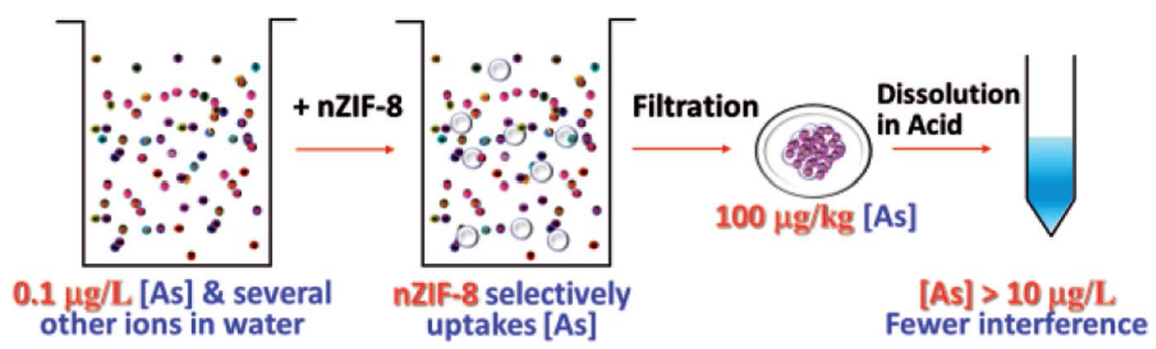

Fig. 1 Schematic illustration of the monitoring method of trace arsenic by selective pre-concentration using ZIF-8.

forms: $\mathrm{As}(\mathrm{III})$ as $\mathrm{H}_{3} \mathrm{AsO}_{3}$, $\mathrm{As}(\mathrm{v})$ as $\mathrm{H}_{3} \mathrm{AsO}_{4}$, or both. Among these forms, $\mathrm{As}(\mathrm{v})$ forms anionic oxides in the wide $\mathrm{pH}$ range of 2-14. Assuming that the $\mathrm{pH}$ of natural water ranges between neutral to slightly acidic, the majority of $\mathrm{As}(\mathrm{v})$ exists as $\mathrm{H}_{2} \mathrm{AsO}_{4}{ }^{-}$or $\mathrm{HAsO}_{4}{ }^{2-}$. As(III) is known to form neutral $\mathrm{H}_{3} \mathrm{AsO}_{3}$ up to $\mathrm{pH}$ 9, and gradual ionization to $\mathrm{H}_{2} \mathrm{AsO}_{3}{ }^{-}, \mathrm{HAsO}_{3}{ }^{2-}$, and $\mathrm{AsO}_{3}{ }^{3-}$ takes place with the increasing $\mathrm{pH} .{ }^{\mathbf{1 1}}$ In this sense, the removal and analysis of $\mathrm{As}(\mathrm{v})$ are considered comparatively as important as those of As(III). For this reason, the quantitative estimation of total arsenic in water is carried out first by oxidizing the As(III) species. $^{12}$

In recent years, zeolitic imidazolate framework 8 (ZIF-8, $\mathrm{Zn}(2 \text {-methylimidazole })_{2}$ ), a metal organic framework, has been reported to be able to uptake anionic arsenic oxide from water. $^{13-19}$ Such studies focused on demonstrating the significantly higher adsorption capacity of ZIF-8 and its capability of lowering arsenic levels to $<10 \mu \mathrm{g} \mathrm{L}^{-1}$. Regarding the removal of arsenic, several cost-effective adsorbents and methods such as electrocoagulation have been widely reported. ${ }^{20-32}$ Therefore, we have focused on the adsorption of arsenic at trace level from systems containing several other ions.

The mechanism of arsenic adsorption by ZIF-8 remains controversial, although some hypotheses have been proposed. ${ }^{\mathbf{1 4 , 1 7}}$ Liu et al. proposed a mechanism involving $\mathrm{Zn}-\mathrm{N}$ bond-cleavage and subsequent adsorption of arsenic oxide on $\mathrm{Zn}$. They also reported that the reduction of the adsorption load during cycle adsorption-desorption tests was due to $\mathrm{Zn}$ leakage. ${ }^{14} \mathrm{Li}$ et al. proposed another mechanism: the generation of a large amount of external active sites $(\mathrm{Zn}-\mathrm{OH})$ through the dissociative adsorption of water and subsequent formation of an inner-sphere complex. ${ }^{17}$

Considering the current status, we set ourselves three aims for this work: one was to identify the lowest arsenic concentration that can be detected. As described above, although the administrative level has been set to $10 \mu \mathrm{g} \mathrm{L} \mathrm{L}^{-1}$, a more accurate method for monitoring and decontamination is highly desirable. The second one was to clarify the arsenic adsorption mechanism by ZIF-8. Finally, we propose a new application where ZIF-8 is used for the pre-concentration of arsenic for determination at the $0.01 \mu \mathrm{g} \mathrm{L}^{-1}\left(=10 \mathrm{ng} \mathrm{L}{ }^{-1}\right)$ level.

Concerning the analysis of arsenic by ICP-MS or colorimetry, interference by coexisting ions remains the main issue. Therefore, high-selectivity materials that are effective even at trace concentrations can not only lead to the enrichment of elements on the adsorbent but also help separate many of the interfering ions in the system from the target analoyte. Therefore, adsorption on ZIF-8, followed by dissolution, may provide a solution providing enriched levels of arsenic and relatively negligible concentrations of most of the other elements present in the feed system (Fig. 1). This specific ability of ZIF-8, in combination with a colorimetric method, for example, has great potential for the monitoring of trace levels of arsenic in a wide variety of water systems, including drinking water and seawater. The final aim of this study was to reduce the measurable arsenic level from $10 \mu \mathrm{g} \mathrm{L}^{-1}$ to at least below $0.1 \mu \mathrm{g} \mathrm{L}^{-1}$, hence reducing the detection limit to $1 / 100$ of the current provisional value.

\section{Experimental}

\subsection{Materials and instrumentation}

2-Methyl imidazole (2Mim) and zinc nitrate (Wako Chemicals) were used for the aqueous synthesis of ZIF-8. Potassium dihydrogen arsenate $\left(\mathrm{KH}_{2} \mathrm{AsO}_{4}\right)$ (Wako Chemicals) was used for the preparation of an $\mathrm{AsO}_{4}{ }^{3-}$ solution. All the reagents used were of analytical grade. Commercially available ZIF-8, Basolite Z1200, was purchased from Sigma Aldrich, Japan, denoted hereafter as bZIF-8. It was used without further treatment for the characterization of the arsenic adsorption from pure water solutions.

The arsenic concentration was mainly analyzed using a Perkin Elmer NexION 300 inductively coupled plasma mass spectrometer. For the estimation of enriched arsenic by a colorimetric method, the MQuant ${ }^{\mathrm{TM}} 117927$ arsenic test kit from Merck KGaA, Germany, was used, with a measurement range of 0.005 to $0.5 \mathrm{mg} \mathrm{L}^{-1}$. The concentration of potassium was analyzed using an Agilent4100 microwave plasma atomic emission spectrometer. A Beckman Coulter Delsa ${ }^{\mathrm{TM}}$ Nano instrument was used for zeta potential measurement. A Bruker D2 Phaser was used to obtain the XRD profiles. FT-IR spectra were recorded on a Thermo Scientific Nicolet iS5 spectrophotometer and SEM images were taken using a Hitachi High Technology S-4800 FE-SEM microscope. Thermogravimetric analysis was performed using a Rigaku Thermoplus Evo TG8120 instrument. The total organic carbon (TOC) and total nitrogen (TN) contents were analyzed using an Analytik Jena Multi N/C 3100 TOC/TN analyzer.

\subsection{Synthesis of ZIF-8 nanoparticles (nZIF-8) in aqueous phase}

The room temperature synthesis ${ }^{\mathbf{3}}$ of nZIF-8 was carried out in the flow using a micromixing system, as shown in Fig. S1. $\dagger$ For 
this, $3.33 \mathrm{~mol} \mathrm{~L}^{-1} 2 \mathrm{Mim}$ prepared in pure water was mixed in flow with a $0.05 \mathrm{~mol} \mathrm{~L}^{-1}$ zinc nitrate solution in pure water. The 2 Mim solution rate was $6 \mathrm{~mL} \min ^{-1}$ while that of zinc nitrate was $2 \mathrm{~mL} \mathrm{~min}^{-1}$. The concentration difference and flow rate overall afforded a mixing ratio of $2 \mathrm{Mim}$-to-zinc nitrate of $200: 1$. T-shaped micromixer with a $0.5 \mathrm{~mm}$ internal diameter was connected to two inlets of the feed solutions and an outlet. The outlet was connected to a $3 \mathrm{~m}$ long microreactor with a $0.5 \mathrm{~mm}$ internal diameter and an additional $60 \mathrm{~m}$ long reactor with a $1.59 \mathrm{~mm}$ internal diameter. The residence times in these reactors were $4.4 \mathrm{~s}$ and $15 \mathrm{~min}$, respectively. Finally, the mixture was collected in a beaker with continuous stirring $(750 \mathrm{rpm})$ to obtain particles with a small size range. The nZIF- 8 obtained in this way was collected by centrifugation at $14000 \mathrm{rpm}$ for $1 \mathrm{~h}$, followed by washing the residue with methanol. The ZIF-8 nanoparticles obtained after washing were denoted nZIF-8 and evaluated for their potential application in trace-level arsenic monitoring.

\subsection{Characterization of ZIF-8}

The composition of both ZIF-8 samples (nZIF-8 and bZIF-8) was determined by measuring the concentration of $\mathrm{Zn}, \mathrm{C}, \mathrm{N}$, and the water content. The water content was estimated based on the TG-DTA profiles obtained in air at a $5{ }^{\circ} \mathrm{C} \min ^{-1}$ heating rate. The XRD profiles of the residues after total oxidation were recorded to identify the oxides formed. Elemental analysis was carried out to measure the total $\mathrm{C}$ and $\mathrm{N}$ contents incorporated in ZIF-8. The concentration of $\mathrm{Zn}$ and any other foreign element in the material was estimated by dissolving ZIF-8 in $1 \mathrm{~mol} \mathrm{~L}^{-1}$ nitric acid solution, followed by ICP-MS analysis. Based on the water content and total $\mathrm{Zn}, \mathrm{C}$, and $\mathrm{N}$ in the material, the compositions of nZIF-8 and bZIF-8 were determined.

So as to compare the size of nZIF-8 prepared in the aqueous phase to that of the commercial sample, FE-SEM images and XRD profiles were obtained. In addition, since the current study aims at the adsorption of trace-level arsenic in water, the zeta potential of the materials was measured to evaluate their dispersion properties.

\subsection{Adsorption of arsenate onto ZIF-8}

Adsorption tests with $\mathrm{AsO}_{4}{ }^{3-}$ on nZIF-8 and bZIF-8 were carried out to compare the adsorption capacities of these materials and elucidate the mechanism of adsorption. For this, solutions of 0.1 to $100 \mathrm{mg} \mathrm{L}^{-1} \mathrm{AsO}_{4}{ }^{3-}$ were prepared by dissolving $\mathrm{KH}_{2} \mathrm{AsO}_{4}$ in pure water. Each solution $(20 \mathrm{~mL})$ was added to $10 \mathrm{mg}$ of the respective adsorbents and mixed at $600 \mathrm{rpm}$ for $1 \mathrm{~h}$ at $25^{\circ} \mathrm{C}$ unless stated otherwise. The mixture was separated by centrifugation for $10 \mathrm{~min}$ at $16000 \mathrm{rpm}$, followed by filtration through a $0.2 \mu \mathrm{m}$ membrane filter (Millipore). The concentration of arsenic before and after adsorption was analyzed by ICP-MS using a calibration curve between 0.1 and $25 \mu \mathrm{g} \mathrm{L}^{-1}$ arsenic prepared in a $2 \%$ nitric acid solution.

Since the purpose of the current work is the demonstration of the potential application of ZIF-8 for monitoring trace-level arsenic in environmental water, the adsorption of $0.01-10 \mu \mathrm{g}$
$\mathrm{L}^{-1} \mathrm{AsO}_{4}{ }^{3-}$ on nZIF-8 was evaluated. In this case, the adsorbent-to-solution ratio was varied from 1000 to $2000 \mathrm{~g}$ $\mathrm{mL}^{-1}$. To determine the effect of coexisting anions, a $0.1 \mu \mathrm{g}$ $\mathrm{L}^{-1} \mathrm{AsO}_{4}{ }^{3-}$ solution was prepared with 1,10 , and $100 \mathrm{mg} \mathrm{L}^{-1}$ solutions of $\mathrm{Cl}^{-}, \mathrm{CO}_{3}{ }^{2-}, \mathrm{NO}_{3}{ }^{-}, \mathrm{SO}_{4}{ }^{2-}$, and $\mathrm{PO}_{4}{ }^{3-}$ from the respective potassium salts. Each solution $(20 \mathrm{~mL})$ was added to $10 \mathrm{mg}$ of nZIF-8 and mixed at $600 \mathrm{rpm}$ and $25^{\circ} \mathrm{C}$ for $1 \mathrm{~h}$. After separation using a $0.45 \mu \mathrm{m}$ filter, the concentration of arsenic was analyzed by ICP-MS. Similarly, adsorption tests at 5, 15, 25 , and $45{ }^{\circ} \mathrm{C}$ were carried out to identify any effect of the mixing temperature.

To clarify the potential application of nZIF-8 for arsenic monitoring in seawater, adsorption tests at $0.1,1$, and $10 \mathrm{mg} \mathrm{L}^{-1} \mathrm{AsO}_{4}{ }^{3-}$ in simulated seawater were carried out. Since at least 100 -fold dilution of seawater is necessary to avoid matrix effects, the starting arsenic concentration should be at least $0.1 \mathrm{mg} \mathrm{L}^{-1}$.

\subsection{Monitoring trace levels of arsenate using nZIF-8}

Monitoring experiments were carried out for the on-site determination of soluble arsenic. For this, $100 \mathrm{mg}$ nZIF- 8 was added to $1 \mathrm{~L}$ of $1,0.1$, and $0.01 \mu \mathrm{g} \mathrm{L}{ }^{-1} \mathrm{AsO}_{4}{ }^{3-}$ solutions. The mixtures were shaken at $130 \mathrm{rpm}$ for $1 \mathrm{~h}$ at room temperature $\left(22{ }^{\circ} \mathrm{C}\right)$. After filtration, the residue was recovered and dissolved in a $1 \mathrm{~mol} \mathrm{~L}^{-1}$ nitric acid solution to measure the enriched concentration. Based on the initial and final concentrations of the solution, and the concentration recovered in the residue, the mass balance was evaluated. In addition to the ICP-MS analysis, the enriched concentration range was estimated using a colorimetric method. In this case, however, since the interference limit of nitrate is quite low $\left(<100 \mathrm{mg} \mathrm{L}^{-1}\right)$, a mixture of hydrochloric acid and sulfuric acid was used to dissolve ZIF-8 while keeping the concentration of interfering ions within the measurable range.

Simulated monitoring experiments were carried out by mixing $3 \mathrm{~L}$ of $0.1 \mu \mathrm{g} \mathrm{L}{ }^{-1}$ of an $\mathrm{AsO}_{4}{ }^{3-}$ solution with $100 \mathrm{mg}$ nZIF8. After hand mixing for a minute, the mixture was left to stand for $1 \mathrm{~h}$ with occasional hand mixing. Then, nZIF-8 was recovered by suction filtration. For the colorimetric estimation of arsenic using MQuant ${ }^{\mathrm{TM}}$ 117927, $60 \mathrm{~mL}$ of the sample solution was used; interference due to foreign substances was found to be quite limiting (as shown in Table $\mathrm{S} 1 \dagger$ ). For this reason, the nZIF-8 residue after adsorption was dissolved in a mixture of $3 \mathrm{~mL} \mathrm{HCl}$ and $1 \mathrm{~mL} \mathrm{H}_{2} \mathrm{SO}_{4}\left(0.5 \mathrm{~mol} \mathrm{~L}^{-1}\right.$ each $)$. By doing so, nZIF8 could be completely dissolved and the concentrations of $\mathrm{Cl}$ and $\mathrm{SO}_{4}{ }^{2-}$ could be maintained below $1000 \mathrm{mg} \mathrm{L}^{-1}$ (the interfering level).

In order for quantitatively estimate arsenic, UV-VIS measurement of the MQuant ${ }^{\mathrm{TM}}$ test stripes was carried out in reflection mode. A calibration curve from 0.005 to $0.15 \mathrm{mg} \mathrm{L}^{-1}$ of arsenic was constructed by plotting the concentration against the peak area of the absorbance between 420 and $800 \mathrm{~nm}$ (Fig. S3 $\dagger$ ). Then, the enriched arsenic level was estimated tentatively from the color of the test stripe. As such, nearly quantitative determination became possible using the calibration curve. 


\section{Results and discussion}

\subsection{Characterization of nZIF-8}

The composition of nZIF-8 prepared in an aqueous system was evaluated in comparison with the commercial bZIF-8. The thermogravimetric analysis confirmed that both materials were nearly free of water (Fig. S2 $\dagger$ ). The weight loss was about $63 \%$ for bZIF- 8 and $65 \%$ for nZIF- 8 and the XRD profiles of the oxidized material confirmed both to contain ZnO. Based on the water content and concentration of $\mathrm{Zn}$ analyzed by total dissolution and $\mathrm{C}, \mathrm{H}, \mathrm{N}$ analysis, the compositions of bZIF-8 and nZIF-8 were determined as $\mathrm{Zn}(2 \mathrm{Mim})_{1.95}$ and $\mathrm{Zn}(2 \mathrm{Mim})_{2.13}$, respectively. This difference suggests that nZIF- 8 is a $2 \mathrm{Mim}$ rich material in comparison to the standard formula $\mathrm{Zn}(2 \mathrm{Mim})_{2}$ of ZIF-8. The excess 2Mim molecules are likely attached to the $\mathrm{Zn}$ (2Mim) particles, as in the case of other water dispersible porous coordination polymers. ${ }^{34}$ In fact, nZIF-8 shows rapid dispersion in the aqueous phase, while bZIF- 8 remained floating on the surface when not stirred. The zeta potential of these two ZIF-8 materials was also found to be remarkably different. bZIF-8 displays a positive value of about $+21 \mathrm{mV}$, in contrast to the zeta potential of about $-30 \mathrm{mV}$ of nZIF-8. This difference can be largely correlated to the Zn-rich and 2Mimrich compositions of the materials. Different zeta potential values could be responsible for the observed dispersion behavior in water.

The SEM images of nZIF-8 (Fig. 2) show homogeneously distributed hexagonal particles, much finer than those of bZIF8. In addition, from the XRD profiles of nZIF-8, the crystallite size was found to be $\sim 43 \mathrm{~nm}$, while that of bZIF-8 was $\sim 65 \mathrm{~nm}$. In the SEM images, the size of nZIF-8 is much finer, indicating the dense aggregation of the nanocrystals of bZIF-8.

\subsection{Adsorption performance with $\mathrm{ng} \mathrm{L}^{-1}$ concentration $\mathrm{AsO}_{4}{ }^{3-}$}

Since our focus was on the lower concentration limit of ZIF-8 adsorption, we performed experiments using initial arsenic solutions with $0.01,0.1,1$, and $10 \mu \mathrm{g} \mathrm{L}^{-1}$ in pure water mixed with nZIF-8 at the liquid to solid ratio $(\mathrm{v} / \mathrm{m})$ of $10000 \mathrm{~mL} \mathrm{~g}^{-1}$. Before that the kinetics of adsorption of low concentration As(v) onto nZIF-8 was studied. For this, a relatively higher starting concentration of about $120 \mu \mathrm{g} \mathrm{L}^{-1}$ was used so that the residual concentration can still be quantitatively measured. This experiment was carried out in $\mathrm{v} / \mathrm{m}$ of 10000 . The adsorption took

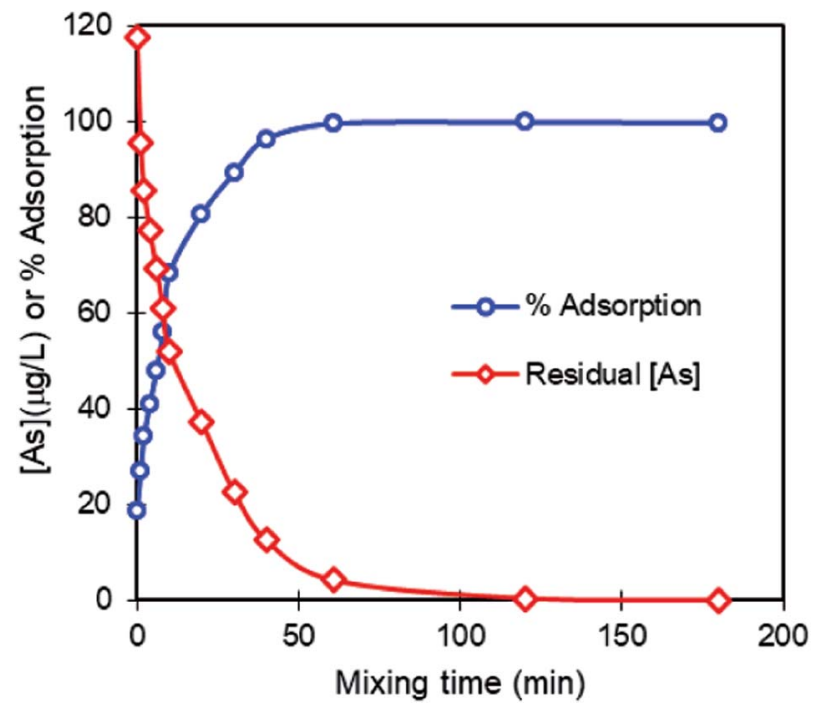

Fig. 3 Kinetics of adsorption of arsenic onto nZIF-8. Initial concentration $=117 \mu \mathrm{g} \mathrm{L}^{-1} .80 \mathrm{mg} \mathrm{nZIF}-8,800 \mathrm{~mL}$ solution, sampling volume $=0.1 \mathrm{~mL}$, replicates $=3$, mixing temperature $=25^{\circ} \mathrm{C}$, mixing rate $=$ $130 \mathrm{rpm}$.

place smoothly and the residual concentration reached 1/1000 of the starting concentration in $1 \mathrm{~h}$, Fig. 3. Irrespective of the high solution volume, achieving near total adsorption demonstrates the high potential of nZIF-8 for the adsorption of arsenic in drinking water.

After observing the kinetics result, $1 \mathrm{~h}$ mixing time was set for all the trace concentration tests. The adsorption rate was investigated by evaluating the equilibrium arsenic concentration in the solution. As shown in Fig. 4(a), almost total adsorption was observed, with less than $1 \%$ standard deviation (5 data points) at $0.1 \mu \mathrm{g} \mathrm{L}^{-1}$ and higher concentrations. We next evaluated the amount of arsenic in nZIF-8 after adsorption. Since ZIF-8 is soluble in acid, it was dissolved in a 5\% nitric acid solution to recover the residue and the enriched concentration of arsenic in said solution was analyzed by ICP-MS. For the concentration $>0.1 \mu \mathrm{g} \mathrm{L}^{-1}$, the mass balance, which is the ratio of the amount of arsenic in the nZIF-8 dissolved solution and the amount of arsenic adsorbed (calculated by the difference between the initial and final arsenic concentrations in the solution phase), was found to be nearly $100 \%$.

Because the final concentration is below the quantifying lower limit of ICP-MS in the case of the initial concentration $0.01 \mu \mathrm{g} \mathrm{L}^{-1}$, both the adsorption and mass balance results show
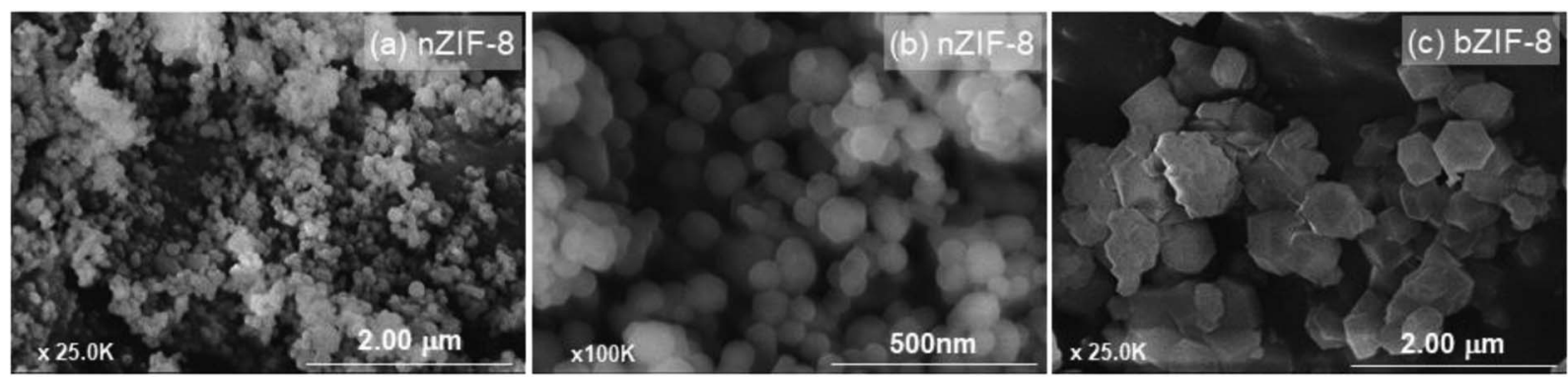

Fig. 2 SEM images showing the finer and homogeneously distributed ( $a$ and b) nZIF-8 particles in comparison with those of (c) bZIF-8. 

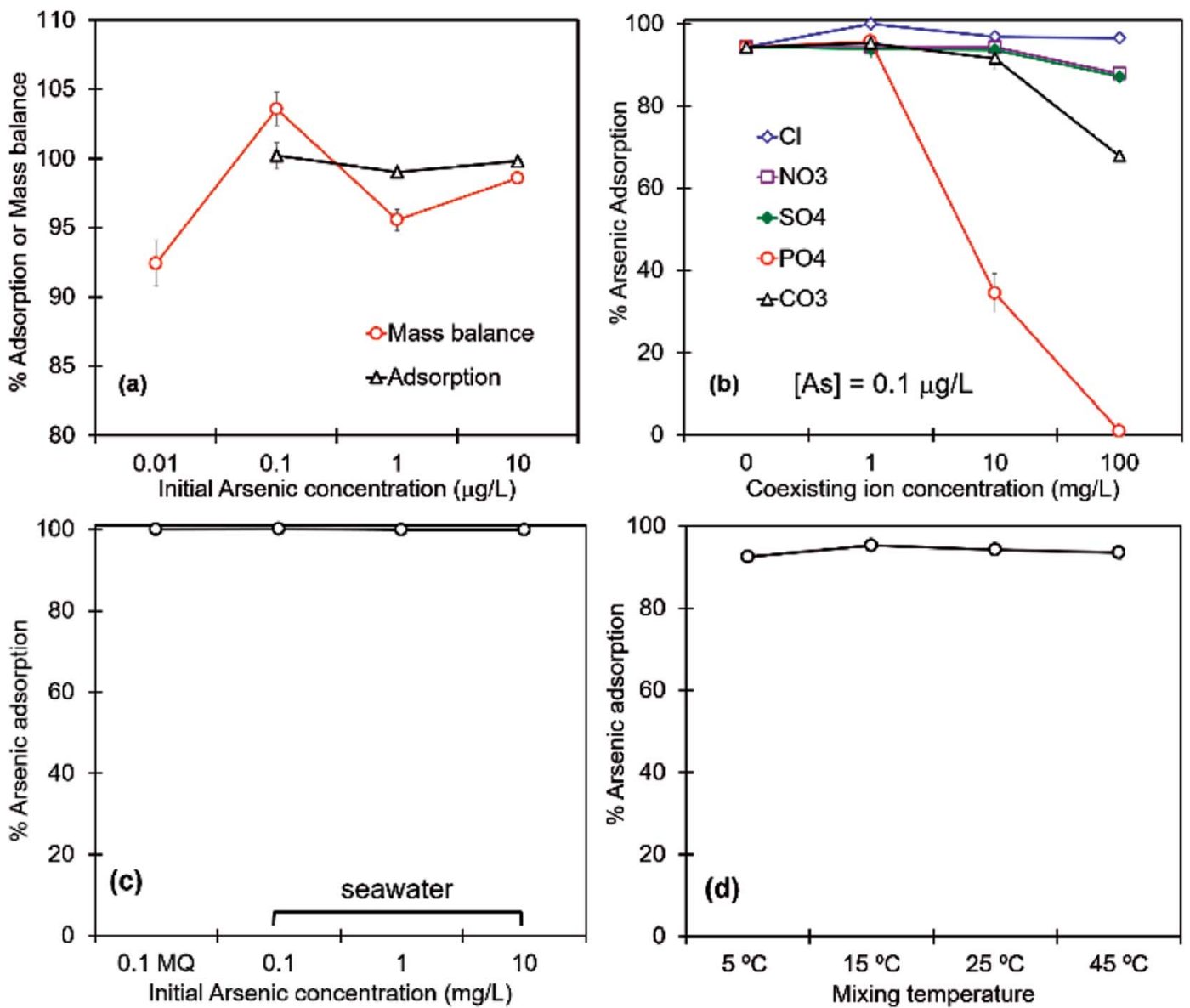

Fig. 4 (a) Enrichment of $0.01-10 \mu \mathrm{g} \mathrm{L}{ }^{-1}$ arsenic in pure water using nZIF- 8 and estimation of the enrichment ratio by analyzing the concen-

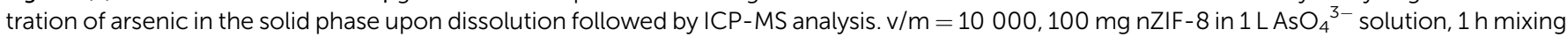
at room temperature, $130 \mathrm{rpm}$. (b) Effect of coexisting ions on the adsorption of arsenic on $\mathrm{nZIF}-8$ for $0.1 \mu \mathrm{g} \mathrm{L}^{-1}$ arsenic in pure water with 1,10 , $100 \mathrm{mg} \mathrm{L}^{-1}$ respective anion in pure water. (c) Arsenic adsorption on nZIF-8 from seawater. (d) Adsorption of $0.1 \mu \mathrm{g} \mathrm{L}{ }^{-1}$ arsenic on $\mathrm{nZIF-8}$ at various temperatures. (b-d) $\mathrm{v} / \mathrm{m}=2000,600 \mathrm{rpm}$ at $25^{\circ} \mathrm{C}$ for $1 \mathrm{~h}$.

large deviations. Therefore, for initial $0.01 \mu \mathrm{g} \mathrm{L} \mathrm{L}^{-1}$ or less, the method can be used only for semi-quantitative estimation.

We also demonstrate that trace arsenic adsorption by nZIF-8 is maintained even in the presence of high-concentrated coexisting anions. The effect of coexisting anions was studied by adding $0.1 \mu \mathrm{g} \mathrm{L}^{-1}$ of an arsenic solution to 1,10 , and $100 \mathrm{mg} \mathrm{L}^{-1}$ solutions of $\mathrm{Cl}^{-}, \mathrm{CO}_{3}{ }^{2-}, \mathrm{SO}_{4}{ }^{2-}, \mathrm{PO}_{4}{ }^{3-}$, and $\mathrm{NO}_{3}{ }^{-}$. As shown in Fig. 4(b), even at $0.1 \mu \mathrm{g} \mathrm{L}^{-1}$ arsenic, the effect of abundant coions was not that disturbing, except for $\mathrm{PO}_{4}{ }^{3-}$, which displays almost the same aqueous chemistry as $\mathrm{AsO}_{4}{ }^{3-}$ (Fig. S3†). Compared to commonly used materials, the adsorption of more than $90 \% \mathrm{AsO}_{4}{ }^{3-}$ from a $0.1 \mu \mathrm{g} \mathrm{L}^{-1}$ solution itself is an impressive outcome. In addition to that, the significantly higher adsorption from solutions containing other anions suggests nZIF-8 as a material with great potential as an arsenic adsorbent.

The experiments with commonly coexisting anions (Fig. 4(b)) suggest the highly selective performance of nZIF-8 for tracelevel arsenic. We then turned our attention to seawater matrices. As such, 0.1 to $10 \mathrm{mg} \mathrm{L^{-1 }}$ arsenic solutions were prepared in artificial seawater (Daigo's Artificial Seawater 395-
01343, sold by Wako Chemicals, Japan). In this case, the initial concentration of arsenic could not be set to less than $10 \mu \mathrm{g} \mathrm{L}^{-1}$ owing to the limitations of ICP-MS analysis. At least 1000 time dilution of seawater is necessary to obtain data free of deviation due to matrix effects of the Na ions. Thus, the starting concentration of arsenic was set at $0.1 \mathrm{mg} \mathrm{L}^{-1}$ and the results were compared to those obtained for a pure water solution (Fig. 4(c)). The outcome is of high application importance as the material selectively recovered a major fraction of $\mathrm{AsO}_{4}{ }^{3-}$. In general, the analysis of low concentration ions in seawater is very difficult owing to its high salinity. However, with the use of nZIF-8, arsenic can be selectively separated from saline water and re-dissolved or extracted affording a concentrated solution with little to no salinity.

For the evaluation of trace arsenic adsorption at different temperatures, the effect of the solution temperature was studied. Adsorption of $0.1 \mu \mathrm{g} \mathrm{L}^{-1} \mathrm{AsO}_{4}{ }^{3-}$ from 5 to $45{ }^{\circ} \mathrm{C}$ was studied at a $\mathrm{v} / \mathrm{m}$ of $2000 \mathrm{~mL} \mathrm{~g}^{-1}$. Since the nZIF-8 powder gets dispersed in water forming fine and translucent microbead-like structures, the effect of the temperature is almost negligible (Fig. 4(d)). At mixing temperatures of $5,15,25$, and $45{ }^{\circ} \mathrm{C}$, 
recoveries of $93 \%$ to $95 \%$ of arsenic were obtained. In other words, under the given conditions, more than $90 \%$ of arsenic in $\mathrm{AsO}_{4}{ }^{3-}$ form, at a concentration level that is otherwise considered undetectable, can be collected and measured after adsorption on nZIF-8.

\subsection{Adsorption mechanism: a ligand exchange process}

For our second aim, the elucidation of the mechanism, a typical adsorption experiment was carried out taking $100 \mathrm{mg} \mathrm{L}^{-1}$ arsenic in the form of $\mathrm{KH}_{2} \mathrm{AsO}_{4}$ in pure water at varying $\mathrm{pH}$ values. The $\mathrm{pH}$ was adjusted using $\mathrm{HCl}$ or $\mathrm{NaOH}$ solutions. As shown in the inset of Fig. 5(a), for $10 \mathrm{mg}$ ZIF- 8 with $20 \mathrm{~mL}$ of the solution, the amount of arsenic adsorbed was higher for nZIF-8. An interesting observation in this experiment is the final solution $\mathrm{pH}$. At acidic to neutral starting $\mathrm{pH}$ values, the value at equilibrium was increased to 8.5-8.9. It was thus interesting to investigate the relation between the solution $\mathrm{pH}$ and the total amount of arsenic adsorbed. For both bZIF-8 and nZIF-8, despite their different respective adsorption loadings, a gradual decrease in the capacity was observed with the increasing initial $\mathrm{pH}$.

Assuming that the increase in the solution $\mathrm{pH}$ is the result of the material dissolution, it would be interesting to observe the changes in the material morphology. The XRD profiles and FTIR spectra (Fig. 5), however, do not show any sharp variations in the structure or functionality after adsorption of a significant amount of $\mathrm{AsO}_{4}{ }^{3-}$. In addition, only a negligible amount of $\mathrm{Zn}$ (less than $5 \mu \mathrm{g} \mathrm{L}^{-1}$ ) was detected in the solution after adsorption, suggesting that almost no Zn in ZIF-8 was released into the solution. A point to note here is that the concentration of $\mathrm{K}$ in the solution from $\mathrm{KH}_{2} \mathrm{AsO}_{4}$ also remained nearly unchanged. Therefore, neither $\mathrm{Zn}$ leaves the ZIF-8 structure nor $\mathrm{K}$ is encapsulated in it. In other words, the adsorption can be considered as either the result of the encapsulation of $\mathrm{AsO}_{4}{ }^{3-}$ or its exchange with the $2 \mathrm{Mim}$ ligand. The increase of the solution
$\mathrm{pH}$ after ZIF-8 addition was the same irrespective of the amount of $\mathrm{KH}_{2} \mathrm{AsO}_{4}$ in the solution or the initial pH. Therefore, it can be concluded that this phenomenon is not necessarily correlated with the adsorption of arsenic.

In order to clarify the adsorption mechanism, an elaborated study using different starting concentrations of $\mathrm{AsO}_{4}{ }^{3-}$ was carried out. Together with the solution $\mathrm{pH}$ as well as the concentration of $\mathrm{K}$ and $\mathrm{Zn}$ in the solution before and after adsorption, the TOC and TN contents of the solution were also determined. For this, $\mathrm{AsO}_{4}{ }^{3-}$ solutions at $1-100 \mathrm{mg} \mathrm{L}^{-1}$ were mixed with nZIF-8 at $2000 \mathrm{~mL} \mathrm{~g}^{-1}$ of solid-to-solution ratio. A typical variation in the amount of adsorption (Fig. S5 $\dagger$ ) with the initial concentration suggests that the process mainly follows single mechanism. Since the solution $\mathrm{pH}$ varies with the concentration of $\mathrm{KH}_{2} \mathrm{AsO}_{4}$, at $1 \mathrm{mg} \mathrm{L}^{-1}$ it is nearly neutral while the $\mathrm{pH}$ of the $100 \mathrm{mg} \mathrm{L}^{-1}$ solution was $\sim 4.2$. Two sets of solutions, one without $\mathrm{pH}$ adjustment and the other with the $\mathrm{pH}$ adjusted to 6 were used. In both cases, the $\mathrm{pH}$ was found to increase to $8.6 \pm 0.2$.

Although $\mathrm{pH}$ shifts and unchanged concentrations of $\mathrm{K}$ and Zn were observed as in the previous cases, large variations in the TOC and TN values were measured. As shown in Fig. 6, a minimum value was obtained, $\sim 0.9 \mathrm{~mol} \mathrm{~kg}^{-1}$ TOC (and the corresponding amount of $\mathrm{TN}$, not shown in the figure), which was the same for nZIF-8 and bZIF-8. This concentration most likely represents the amount of $2 \mathrm{Mim}$ required to increase the solution $\mathrm{pH}$ to the favored weakly alkaline value of $8.6 \pm 0.2$. However, when the concentration of arsenic was over $1 \mathrm{mg} \mathrm{L}^{-1}$, a linear increase in the TOC and TN values was observed, corresponding to the amount of 2Mim dissolved in the solution phase. This trend was also observed for the commercial bZIF-8 sample. Since the solution pH remains at about 8.6, the majority of $\mathrm{AsO}_{4}{ }^{3-}$ is expected to exist as $\mathrm{HAsO}_{4}{ }^{2-}$. Therefore, the expected exchange takes place according to eqn (1), releasing two moles of $2 \mathrm{Mim}$ per mole of adsorbed arsenic.
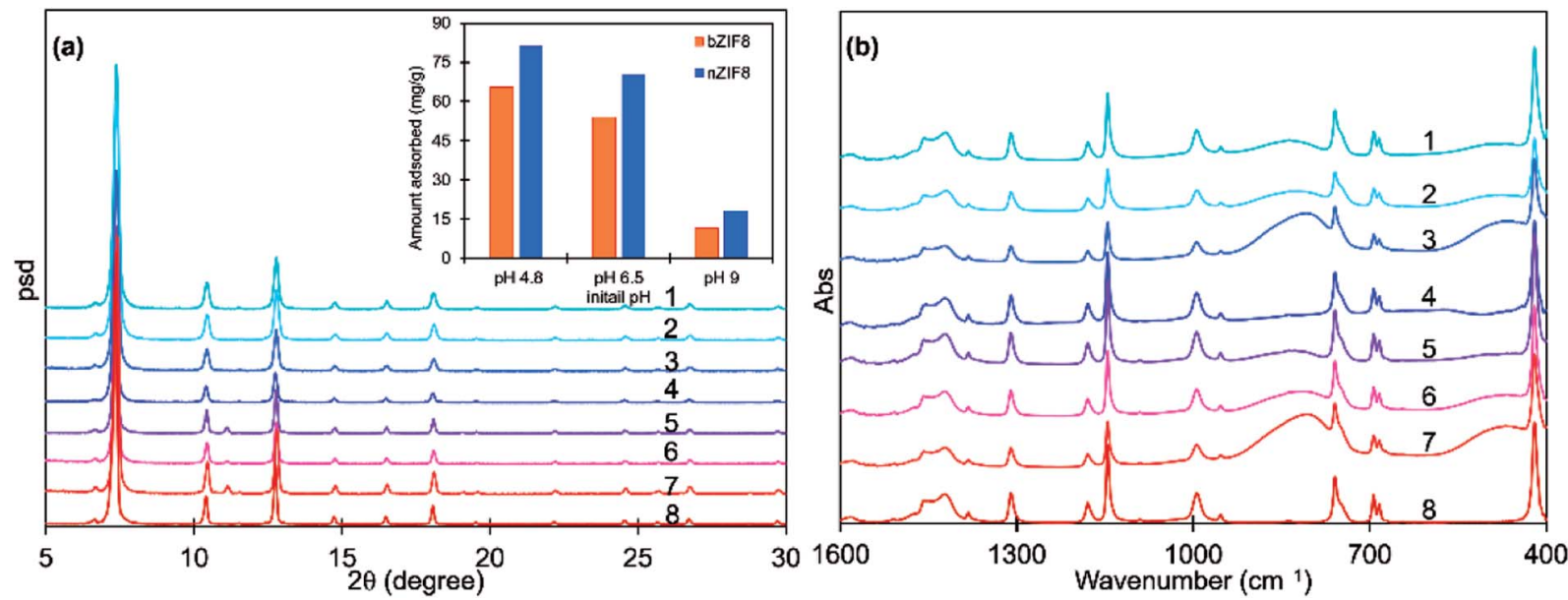

Fig. 5 (a) XRD profiles and (b) FT-IR spectra of bZIF-8 and nZIF- 8 confirming that the ZIF- 8 structure has been maintained after adsorption of high-concentration arsenic under different pH conditions. Legend: (1) nZIF-8 pH 9; (2) nZIF-8 pH 6.5; (3) nZIF-8 pH 4.8; (4) Pure nZIF-8; (5) bZIF$8 \mathrm{pH}$ 9; (6) bZIF-8 pH 6.5; (7) bZIF-8 pH 4.8; (8) Pure bZIF-8. The inset in (a) shows the decrease in the arsenic adsorption capacity of ZIF-8 with

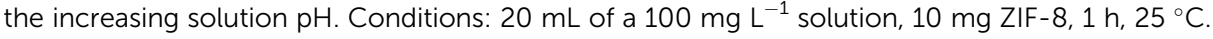




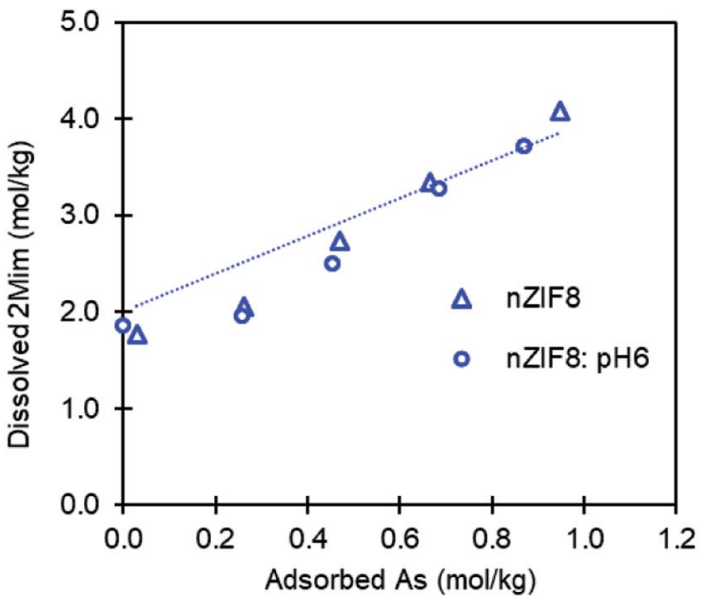

Fig. 6 Dissolved 2Mim (TOC-based) showing the mole to mole exchange of $\mathrm{HAsO}_{4}{ }^{2-}$ with $2 \mathrm{Mim}$.

$$
\mathrm{Zn}\left(\mathrm{C}_{4} \mathrm{H}_{5} \mathrm{~N}_{2}\right)_{2}+\mathrm{HAsO}_{4}{ }^{2-} \rightarrow \mathrm{ZnHAsO}_{4}+2 \mathrm{C}_{4} \mathrm{H}_{5} \mathrm{~N}_{2}^{-}
$$

This outcome suggests that the increased solution $\mathrm{pH}$ and adsorption of $\mathrm{AsO}_{4}{ }^{3-}$, respectively, occurs at the cost of $2 \mathrm{Mim}$ molecules from ZIF-8. Also, as explained in the previous section, the $\mathrm{XRD}$ profile of the $\mathrm{AsO}_{4}{ }^{3-}$-adsorbed material was, in general, consistent with that of pristine ZIF-8. Overall, the uptake of $\mathrm{AsO}_{4}{ }^{3-}$ takes place basically by replacing the $2 \mathrm{Mim}$ anions in the ZIF-8 framework with $\mathrm{H}_{2} \mathrm{AsO}_{4}{ }^{2-}$, maintaining the structure up to at least $90 \mathrm{mg}$ of adsorbed arsenic per gram of material. However, if the adsorbate is arsenite, As(III), since its oxide remains in neutral form in the $\mathrm{pH}$ range of drinking water, a different mechanism is expected. Relatively lower capacity for As(III) and the deformation of the crystal structure after its adsorption, which was not observed in the present study suggest the possibility of a different driving mechanism. ${ }^{14,15}$

\subsection{Application for the analysis of arsenic levels below the WHO-recommended level}

As described above, nZIF-8 exhibits high adsorption performance toward arsenic even at the ng $\mathrm{L}^{-1}$ level in aqueous solution. However, its repeated utilization for decontamination would be unfeasible, because a certain level of $2 \mathrm{Mim}$ is eluted every time arsenic is adsorbed. However, its use for the preconcentration of arsenic before conventional analysis is promising. If a 100-fold concentrated arsenic solution could be obtained using nZIF-8, the limit of quantification of a conventional method could be lowered by that magnitude. In principle, for example in combination with ICP-MS or colorimetry methods, the minimum limits of 0.1 and $10 \mu \mathrm{g} \mathrm{L}^{-1}$, respectively, would be reduced to 0.001 and $0.1 \mu \mathrm{g} \mathrm{L}^{-1}$ arsenic by means of a pre-concentration step by nZIF-8.

It is well known that the concentration of arsenic itself in flowing waters varies with the location. For example, in Japanese rivers, the arsenic concentration is below $2 \mu \mathrm{g} \mathrm{L}^{-1}$ with an average of $0.57 \mu \mathrm{g} \mathrm{L}^{-1}$. However, the average concentrations of
$\mathrm{Cl}^{-}, \mathrm{NO}_{3}{ }^{-}$, and $\mathrm{SO}_{4}{ }^{2-}$ are $4.6,1.6$, and $7.4 \mathrm{mg} \mathrm{L}^{-1}$, respectively. The average concentration of phosphorus, which includes the highly competing $\mathrm{PO}_{4}{ }^{3-}$ ion, is $12.1 \mu \mathrm{g} \mathrm{\textrm {L } ^ { - 1 }}$, a value which presents almost no effect on the adsorption of trace-level $\mathrm{AsO}_{4}{ }^{3-}$ on nZIF-8.

The provisional value by the WHO is below $10 \mu \mathrm{g} \mathrm{L}^{-1}$ and it is the same in many countries. The term provisional suggests that the value has not been proved yet as safe; moreover, it will need updating once more suitable methodologies are developed. Under such circumstances, nZIF-8, which offers highly selective uptake of soluble arsenic oxyanions (except in the presence of $100 \mathrm{mg} \mathrm{L}^{-1} \mathrm{PO}_{4}{ }^{3-}$ ), could be used for concentration followed by quantitative estimation. The high selectivity of nZIF-8 for arsenic adsorption is a key factor for systems such as seawater or industrial water consisting of other elements. When counter ions hamper the reliable analysis by ICP-MS for high precision determination, this scheme of selective uptake on nZIF-8, followed by dissolution to afford a solution with a higher arsenic concentration and manageable matrix effects, offers clear advantages. For practical analysis, adsorption followed by colorimetric analysis is preferred. However, one should keep in mind the limitations of the test kits themselves. The only limitation to consider when using MQuant ${ }^{\mathrm{TM}}$, the kit employed in the current study, is the use of an acidic solution to dissolve nZIF-8.

Upon achieving the successful concentration of as low as $0.01 \mu \mathrm{g} \mathrm{L}^{-1}$ arsenic using nZIF-8, realistic experiments using 0.5-300 ng L ${ }^{-1}$ solutions in pure water, nZIF-8, a $5 \mathrm{~L}$ bottle for the adsorption process, a filtration system with a $0.45 \mu \mathrm{m}$ membrane filter, and the MQuant ${ }^{\mathrm{TM}}$ colorimetric kit were carried out. In order to ascertain the degree of enrichment not only by visual comparison of the colored stripes with the MQuant ${ }^{\mathrm{TM}}$ 's standard color/concentration spectrum, a calibration curve using UV-Vis spectroscopy in reflection mode at concentrations of $0.005-0.15 \mathrm{mg} \mathrm{L}^{-1}$ arsenic was constructed by plotting the peak area between 420 and $750 \mathrm{~nm}$ (Fig. S5†). This plot, which passes through the origin, presents an $R^{2}$ value of 0.998 and a slope of 1397.2. Using this plot, quantitative estimation of the arsenic content in the color stripe was achieved. For solutions in fresh water, the kit could estimate traces of arsenic with $90-106 \%$ accuracy (Table 1). However, only $42 \%$ accuracy was obtained for $100 \mathrm{ng} \mathrm{\textrm {L } ^ { - 1 }}$ arsenic in seawater.

In fresh water, this preliminary work aimed for the monitoring of trace concentration arsenic has shown the highly positive result. The next step in this regard would be making the process more feasible for the field tests. For this, the process will be repeated taking the simulated or real contaminated water. Also, because the size of nZIF-8 is $<50 \mathrm{~nm}$, work on making nZIF-8 film or membrane will be carried out so that the filtration step in the presented scheme can be avoided. In addition, the discussion on arsenite, As(III), is intentionally avoided in this work. The primary reason is to focus on explaining the so far vague mechanism of arsenic oxide anion adsorption by ZIF-8. Regarding the application, because several works have demonstrated the adsorption of substantial concentration of the arsenite by ZIF-8, we expect that the results discussed in this work can be replicated for the arsenite as well. 
Table 1 Results showing the concentration followed by detection of $\mathrm{ng} \mathrm{L}^{-1}$ level arsenic in freshwater and seawater using nZIF- 8 and MQuant kit. Solution volume: initial $=3000 \mathrm{~mL}$, final $=60 \mathrm{~mL}$. nZIF- $8=100 \mathrm{mg}$

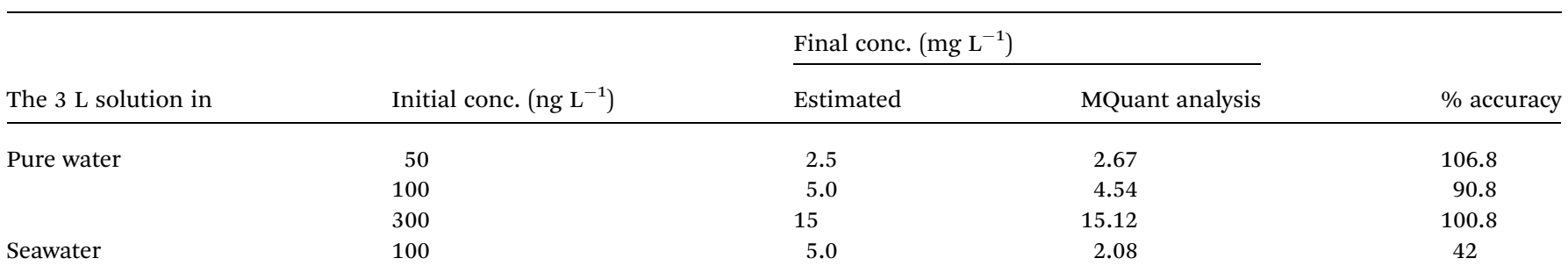

\section{Conclusion}

nZIF-8 prepared in the aqueous phase with negative zeta potential is found to be highly dispersible in water. This property is expected to ease the adsorption of trace concentration arsenate in a large solution to material ratio. Almost complete adsorption of $10 \mathrm{ng} \mathrm{L}^{-1}$ arsenate onto nZIF-8 is an encouraging outcome for the monitoring purpose. However, because the arsenate adsorption is confirmed to be a ligand exchange process, ZIF-8 cannot be recommended for the decontamination application, even though the material offers a very high adsorption capacity. The monitoring-oriented experiment coupled with the handy colorimetric tool showed a high precision result. This outcome can certainly be implemented in the regions where the analysis of below $\mathrm{mg} \mathrm{L}^{-1}$ arsenic is still a big deal. Because nZIF- 8 is obtained in $<50 \mathrm{~nm}$ size, it can be fabricated into membrane or film form so that the process becomes even handier. Real application oriented work taking arsenate contaminated water and the nZIF-8 film is going on.

\section{Conflicts of interest}

There are no conflicts to declare.

\section{Acknowledgements}

The authors are thankful to Hiromi Noguchi, Masami Kawakami, and Koji Sakurai for their technical assistance.

\section{References}

1 U. K. Chowdhury, B. K. Biswas, T. R. Chowdhury, G. Samanta, B. K. Mandal, G. C. Basu, C. R. Chanda, D. Lodh, K. C. Saha, S. K. Mukherjee, S. Roy, S. Kabir, Q. Quamruzzaman and D. Chakraborti, Environ. Health Perspect., 2000, 108, 393-397.

2 A. Pal, U. K. Chowdhury, D. Mondal, B. Das, B. Nayak, A. Ghosh, S. Maity and D. Chakraborti, Environ. Sci. Technol., 2009, 43, 3349-3355.

3 M. Amini, K. C. Abbaspour, M. Berg, L. Winkel, S. J. Hug, E. Hoehn, H. Yang and C. A. Johnson, Environ. Sci. Technol., 2008, 42, 3669-3675.

4 R. Smith, R. Knight and S. Fendorf, Nat. Commun., 2018, 9, 2089.
5 WHO, Guidelines for Drinking-water Quality, 3rd edn, 2016, vol. 1, ISBN 9241546387.

6 R. K. Dhar, Y. Zheng, J. Rubenstone and A. van Geen, Anal. Chim. Acta, 2004, 526, 203-209.

7 F. T. Henry, T. O. Kirch and T. M. Thorpe, Anal. Chem., 1979, 51, 215-218.

8 Y. Song and G. M. Swain, Anal. Chem., 2007, 79, 2412-2420. 9 Y. He, Y. Zheng, M. Ramnaraine and D. C. Locke, Anal. Chim. Acta, 2004, 511, 55-61.

10 L. Bu, T. Gu, Y. Ma, C. Chen, Y. Tan, Q. Xie and S. Yao, J. Phys. Chem. C, 2015, 119, 11400-11409.

11 P. L. Smedley and D. G. Kinniburgh, Appl. Geochem., 2002, 17, 517-568.

12 B. Petrusevski, S. Sharma, J. Schippers and K. Shordt, Arsenic in Drinking Water, 2007, vol. 17, pp. 3-24.

13 B. K. Jung, J. W. Jun, Z. Hasan and S. H. Jhung, Chem. Eng. J., 2015, 267, 9-15.

14 M. Jian, B. Liu, G. Zhang, R. Liu and X. Zhang, Colloids Surf., A, 2015, 465, 67-76.

15 B. Liu, M. Jian, R. Liu, J. Yao and X. Zhang, Colloids Surf., A, 2015, 481, 358-366.

16 A. J. Howarth, Y. Liu, J. T. Hupp and O. K. Farha, CrystEngComm, 2015, 17, 7245-7253.

17 J. Li, Y. Wu, Z. Li, B. Zhang, M. Zhu, X. Hu, Y. Zhang and F. Li, J. Phys. Chem. C, 2014, 118, 27382-27387.

18 Z. Zou, S. Wang, J. Jia, F. Xu, Z. Long and X. Hou, Microchem. J., 2016, 124, 578-583.

19 Y.-N. Wu, M. Zhou, B. Zhang, B. Wu, J. Li, J. Qiao, X. Guan and F. Li, Nanoscale, 2013, 6, 1105-1112.

20 S. E. Amrose, S. R. S. Bandaru, C. Delaire, C. M. van Genuchten, A. Dutta, A. DebSarkar, C. Orr, J. Roy, A. Das and A. J. Gadgil, Sci. Total Environ., 2014, 488-489, 539-546.

21 C. M. Van Genuchten, S. E. A. Addy, J. Peña and A. J. Gadgil, Environ. Sci. Technol., 2012, 46, 986-994.

22 L. Li, C. M. Van Genuchten, S. E. A. Addy, J. Yao, N. Gao and A. J. Gadgil, Environ. Sci. Technol., 2012, 46, 12038-12045.

23 A. Gupta, V. S. Chauhan and N. Sankararamakrishnan, Water Res., 2009, 43, 3862-3870.

24 K. Gupta, T. Basu and U. C. Ghosh, Engineering, 2009, 22222228.

25 C. Hang, Q. Li, S. Gao and J. K. Shang, Ind. Eng. Chem. Res., 2012, 51, 353-361.

26 C.-S. Jeon, K. Baek, J.-K. Park, Y.-K. Oh and S.-D. Lee, J. Hazard. Mater., 2009, 163, 804-808. 
27 S. Luther, N. Borgfeld, J. Kim and J. G. Parsons, Microchem. J., 2012, 101, 30-36.

28 A. Maiti, J. K. Basu and S. De, Chem. Eng. J., 2012, 191, 1-12. 29 S. M. Maliyekkal, L. Philip and T. Pradeep, Chem. Eng. J., 2009, 153, 101-107.

30 C. A. Martinson and K. J. Reddy, J. Colloid Interface Sci., 2009, 336, 406-411.

31 G. S. Zhang, J. H. Qu, H. J. Liu, R. P. Liu and G. T. Li, Environ. Sci. Technol., 2007, 41, 4613-4619.
32 M. L. Chen, Y. Sun, C. B. Huo, C. Liu and J. H. Wang, Chemosphere, 2015, 130, 52-58.

33 D. Yamamoto, T. Maki, S. Watanabe, H. Tanaka, M. T. Miyahara and K. Mae, Chem. Eng. J., 2013, 227, 145150.

34 A. Gotoh, H. Uchida, M. Ishizaki, T. Satoh, S. Kaga, S. Okamoto, M. Ohta, M. Sakamoto, T. Kawamoto, H. Tanaka, M. Tokumoto, S. Hara, H. Shiozaki, M. Yamada, M. Miyake and M. Kurihara, Nanotechnology, 2007, 18, 345609. 